\title{
The influence of main emulsion components on the physicochemical properties of soursop beverage emulsions: a mixture design approach
}

\begin{abstract}
The physicochemical properties of soursop beverage emulsion were investigated using mixture design. Results indicated that the regression models were significantly fitted for all response variables studied, except creaming index at $10^{\circ} \mathrm{C}$. Interactions between biopolymers and oil phase had the most significant effect on creaming stability; however, modified starch played a much prominent role in maintaining the cloudiness and average droplet size. Meanwhile, WPI contributed significantly to the conductivity of the emulsions. The optimum condition resulted in desirable physicochemical properties could be achieved using $8.70 \%$ (w/w) modified starch, 1.02\% (w/w) WPI, 10.11\% (w/w) flavor oil, and 76.57\% (w/w) water.
\end{abstract}

Keyword: Mixture design; Modified starch; Physicochemical properties; Soursop beverage emulsion; Whey protein isolate 